\title{
Development of Pedestrian Alert System for Use in Electric Vehicles
}

\author{
Nikola FRLIĆ SEKULIĆ, Ivan BLAGOJEVIĆ, Vladimir POPOVIĆ, Dragan STAMENKOVIĆ, Slobodan JANKOVIĆ
}

\begin{abstract}
Modern technology has made electric vehicles more accessible, which is important for the preservation of the environment. Although eco-friendly, from the standpoint of pedestrian safety, they may be baleful. The low levels of noise emitted by electric vehicles at speeds lower than $20 \mathrm{~km} / \mathrm{h}$ are not sufficient for the pedestrian to become aware of the approaching vehicle based on sound. The topic of this paper is the research of sounds used to warn pedestrians of an incoming electric vehicle, while the goal is to single out the most suitable applicable sound based on an unique self-developed multiparameter methodology (which has been experimentally proved). The paper contains the results of the experiments, both of selecting the most suitable applicable sound and driving-range testing.
\end{abstract}

Keywords: electric vehicles; noise; pedestrian; safety

\section{INTRODUCTION}

Hybrid electric vehicle (HEV) and electric vehicle (EV) emit less noise than conventional internal combustion engine (ICE) vehicles. The primary concern about pedestrian safety is related to situations when electric vehicle is travelling at low speed, emitting noise too low to be a warning for pedestrian. In those cases noise produced by tires and air flow is minimal [1].

In one Japanese study, performed in 2010, the noise emitted by an ICE vehicle was measured and compared to the noise emitted by a hybrid vehicle working in electric mode. According to the data obtained in this experiment, an HEV emitted approximately the same level of noise as a traditional vehicle at speeds higher than $20 \mathrm{~km} / \mathrm{h}$ because, at those speeds, the noise produced by tires exceeds the level of noise emitted by an ICE. Mechanical, aerodynamic and tire noise are primary sounds emerging from a moving vehicle [2].

The data published by National Highway Traffic Safety Administration (NHTSA) refers to the period between 2009 and 2011 and is related to the number of traffic accidents involving pedestrians, HEV and ICE vehicles [3]. In the report published by NHTSA, it is stated that the probability of a pedestrian being involved in an accident with a HEV is $35 \%$ higher compared to the probability of being involved in one with an ICE vehicle. The results were obtained based on 186 hybrid vehicles and 5699 ICE vehicles that participated in traffic accidents involving pedestrians in the USA. Furthermore, the National Highway Traffic Safety Administration, using the pedestrian crash data from 12 states, documented that the accident rate of HEVs was twice as high as that of the ICE vehicles in low-speed manoeuvre conditions, including slowing, stopping, backing up, and entering a parking space.

In a study which examined people's beliefs about the safety of pedestrians and drivers in relation to quiet vehicles results showed that $86 \%$ of subjects stated that sounds emitted by the movement of the vehicle made them more aware of its location and direction. In addition, most participants $(73 \%)$ said that they have used vehicle noise as a cue of an approaching vehicle when crossing a street [4].

Currently available statistical data on traffic accidents compares mostly hybrid and ICE vehicles. The absence of data pertaining to electric vehicles may be explained by a small sample on the global level. If we compare hybrid vehicles with electric vehicles by the level of noise emitted, we can conclude that electric vehicles can only be less favourable when it comes to pedestrian safety, since (unlike hybrid vehicles) they do not use an ICE.

\section{DEVELOPMENT OF THE PEDESTRIAN ALERT SYSTEM}

The development of the pedestrian alert system consisted of two parts. The first part was to find the most suitable alert sound based on the opinion of subjects. The second part was the experimental testing of three selected sounds (obtained in the first part) and measuring the reaction time of subjects posing as pedestrians.

\subsection{Survey to Find Most Suitable Sounds to Test}

There are multiple important factors needed to be considered for the selection of most suitable sounds. The 300-600 Hz range was chosen for three reasons:

- The frequencies are in the range of voiced speech.

- Availability and the price of speakers that can reproduce sounds of these frequencies

- People older than 60 have difficulty detecting sounds with frequencies higher than $2 \mathrm{kHz}$ [5].

In one study participants were asked for recommendations for type of artificial sound that could be added like additional sound to the quiet vehicles. $40 \%$ of the participants preferred hum sound [6]. By combining four different frequencies with four different waves, we obtained 16 tonnes on which we based the first part of the test, as shown in Tab. 1. The frequency of the amplitude of the tones generated during the testing was $2 \mathrm{~Hz}$.

Since there are no precise evaluation parameters to define alert sounds, terms alertability, irritancy and authenticity were adopted as criteria for choosing the most suitable sound.

Alertability is a very important characteristic of alert sounds. People are accustomed to recognizing the sound of an approaching vehicle as potentially dangerous. However, they are still not accustomed to recognizing and linking the alert system sound with a vehicle. For this reason, it is necessary that the chosen sound for this system has the capability of alerting a pedestrian that hears it for the first time. 


\begin{tabular}{|l|l|l|l|l|l|}
\hline \multicolumn{2}{|c|}{ Table 1 Sounds used in the testing } \\
\hline Wave type & $300 \mathrm{~Hz}$ & $400 \mathrm{~Hz}$ & $500 \mathrm{~Hz}$ & $600 \mathrm{~Hz}$ \\
\hline & Sound1 & Sound2 & Sound3 & Sound4 \\
\hline & Sound5 & Sound6 & Sound7 & Sound8 \\
\hline & & Sound9 & Sound10 & Sound11 & Sound12 \\
\hline & & Sound13 & Sound14 & Sound15 & Sound16 \\
\hline
\end{tabular}

A low level of irritancy of the sound does not impact only the pedestrians, but everyone else too. On the other hand, a high level of irritancy of an alert sound would have a negative impact on people living near busy streets, particularly in the vicinity of schools and hospitals. The level of irritancy depends on the frequency of that tone, its intensity, and the wave shape.

Confirming the authenticity of the sound is necessary to avoid the possibility of pedestrians mistaking the sound for another. It is common for the sound produced by a moving vehicle to reflect off of obstacles in the vicinity so that the pedestrian cannot identify the position and the direction of a moving vehicle based on hearing alone.

However, a well-known sound of a vehicle will alert the pedestrian and they can use other senses to notice it. Thus, it is necessary for the alert system sound to be unique, so as to reduce the possibility of pedestrians ignoring the sound. This is why melodic sounds that can be mistaken for cell phone sounds or music should be avoided.

Sound annoyance can cause frustration and affect personal daily routine, and, when constant, lead to hypertension [7]. The irritancy, alertability and the authenticity of the sounds were determined by interviewing subjects. Best-rated sounds were classified into a new, narrower aggregate. It was necessary to experimentally test the alertability from the new aggregate to choose the sound that would promptly alert the pedestrians of the oncoming vehicle, with the lowest possible level of irritancy. This was done by interviewing 82 subjects.

Each of the subjects was given a detailed explanation of the experiment they were participating in. Sound level was $65 \mathrm{~dB}(\mathrm{~A})$ at $1 \mathrm{~m}$ away from the standing respondent (all sound level measurements made for the purpose of this research were conducted using a calibrated Lutron SL4001 sound level meter positioned at the level of $1,5 \mathrm{~m}$ from the ground). The duration of each individual tone was $10 \mathrm{~s}$.

During data analysis it was agreed upon to set the irritancy of a sound as first priority with a weighting coefficient of 0,6 . The alertability of the sound was set as the second priority with a weighting coefficient of 0,3 . The authenticity of the sound was set as the third priority with a weighting coefficient of 0,1 .

The reasons for the significantly higher weighting coefficient of irritancy than that of alertability are:

- Alertability will be tested in detail later on in the experiment;

- The sound emitted by an ICE vehicle is not particularly alertable. However, people are accustomed to even that sound representing potential danger. This is why using a very irritating sound to indicate great danger is not necessary;

- The necessity for low irritancy is caused by a high number of vehicles moving in close vicinity to pedestrians.

Alertability was determined based on these three indicators:

- Noticeability of the sound;

- The ability of the sound to draw attention;

- The ability of the sound to keep the attention.

The necessity for confirming the authenticity of sounds arose from the possibility of mistaking the sound emitted by the vehicle with any other environmental sound.

Most of the systems introduced by EV manufacturers use only vehicle speed as an input parameter [8]. The alert sound should start being produced at speeds of $2 \mathrm{~km} / \mathrm{h}$. Lower speeds are irrelevant since at these speeds (2,5 times slower than natural pedestrian pace) the risk of contact between the vehicle and the pedestrian is minimal. Therefore, it is necessary to produce the sound at speeds faster than $2 \mathrm{~km} / \mathrm{h}$. However, an upper speed-limit under which the sound will be produced needs to be determined. For that purpose, we can use the speed of $20 \mathrm{~km} / \mathrm{h}$ so that the discontinuation of the sound is replaced by the noise produced naturally by tires and air resistance. Monitoring of the speed of the vehicle can be done through On-board diagnostics (OBD) or CAN [9].

While driving in reverse, the driver has reduced visibility, especially during the night when lighting is lower from the rear of the vehicle. This is why it is necessary for the pedestrian to be able to hear the vehicle.

It is necessary to find the appropriate moment to hear the oncoming vehicle and whether there are adverse effects of premature realization as well as when it is too late to become aware of the oncoming vehicle.

Therefore, we need to consider realistic situations in which the pedestrian needs to notice the oncoming vehicle, and what is the minimum distance at which the pedestrian will become aware of it. It is of great importance for the pedestrian to (through the sense of hearing) notice the vehicle coming from the side or the rear. The most attention needs to be dedicated to speeds between 8 and 15 $\mathrm{km} / \mathrm{h}$, since at those speeds electric vehicle emits noise between 45 and $55 \mathrm{~dB}(\mathrm{~A})$ [10], with average environment noise being 45 to $59 \mathrm{~dB}(\mathrm{~A})$ [11], which makes the vehicle less noticeable. A difference of around $6 \mathrm{~dB}$ corresponds to a doubling of the physical intensity of the sound [12]. There is a 0,8 to 1,5 s delay between the moment when the 
driver notices a road obstacle and deceleration of the vehicle (depending on the driver's skill and fatigue) [13]. That time interval entails the time needed to notice the obstacle, to decide whether it is necessary to decelerate or not, to move the leg from the accelerator pedal to the brake pedal, cancel the braking system gap and reaching the necessary brake force. Considering the stated time period (on a road with a friction coefficient of $\varphi=0,7$ ) the braking distance varies between 2,85 and 5,65 $\mathrm{m}$ (depending on the driver's fatigue) at $10 \mathrm{~km} / \mathrm{h}$. Regarding the capabilities of the driver and the vehicle, if we adopt the least favourable value of braking distance and the driver's reaction time $(1,5$ $\mathrm{s})$, the resulting minimum distance of noticing an oncoming vehicle is $9,82 \mathrm{~m}$.

\subsection{Experimental Testing}

The experimental testing of attained data was done in a driving range with a marked trajectory for the vehicle moving at the constant speed of $10 \mathrm{~km} / \mathrm{h}$. The position of the respondent was marked as well. Electric vehicle Volkswagen UP was used in this test (Fig. 1). The design concept [14] (regarding the number and the position of electric engines) that was used for this vehicle was frontengine with a front-wheel-drive. Fifteen subjects posed as pedestrians positioned on the sidewalk with the intention of crossing the street. Subjects were positioned on the left and the right side of the marked trajectory (Fig. 2) in such a way that they could not perceive the vehicle visually. Three sets of testing were executed for each of the four variations (Three chosen sounds and no sound). Subjects changed places to be placed on both the left and the right side of the vehicle. This setting resulted in 180 individual pieces of data.
The electric vehicle was mounted with a sound generating speaker (Fig 3). The vehicle started its motion $50 \mathrm{~m}$ away from the subjects. At $40 \mathrm{~m}$ away from the subjects, the vehicle achieved the set speed. In the range of $20 \mathrm{~m}$ between the subjects and the vehicle, the trajectory was visibly divided into $1 \mathrm{~m}$ segments, by which the distance at which the vehicle was registered (noticed) was determined. The vehicle stopped its motion after passing by the subjects. The testing was recorded by cameras in appropriate positions, followed by summarizing the results.

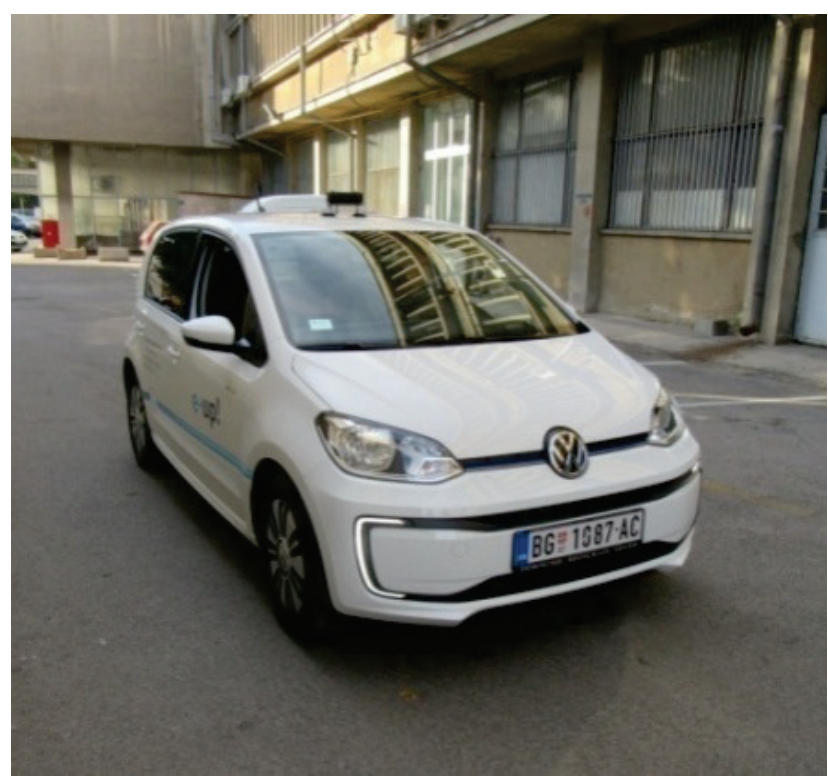

Figure 1 The vehicle used for testing

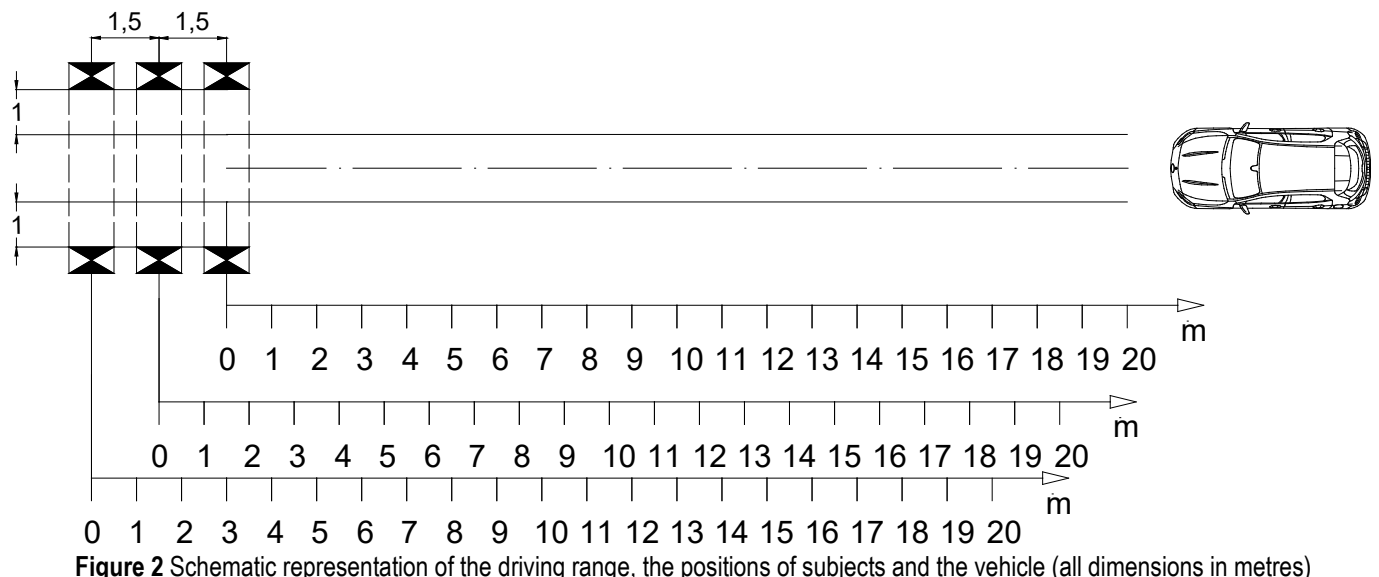

The quality of asphalt in the driving range was satisfactory regarding the surface characteristics (in an earlier experiment, the coefficient of adhesion was estimated by measuring the braked trailer towing force to be around 0,7 , and rolling resistance coefficient was estimated to be around 0,012 at the speeds used in this test by measuring the unbraked trailer towing force), as well as regarding the macro and micro relief. Aside from the environment noise that averaged at $47 \mathrm{~dB}(\mathrm{~A})$ an additional noise was simulated by a diesel engine vehicle at $3 \mathrm{~m}$ away from the subjects with the sound level of $58 \mathrm{~dB}(\mathrm{~A})$.

\section{RESULTS OF THE EXPERIMENT}

Mean values of alertability, irritancy and authenticity for all 16 tonnes were obtained by processing the data gathered from the questionnaire. The curves representing different wave functions of the sound depending on their frequency and mean value of their rating are shown in Fig. 4. After calculating in the weighting coefficients for the alertability, irritancy and authenticity overall ratings of tones were determined, as shown in Fig. 5.

Three tones with best overall ratting were chosen for experimental testing:

- Frequency $600 \mathrm{~Hz}$, sine wave, 
- Frequency $400 \mathrm{~Hz}$, triangular wave and

- Frequency $400 \mathrm{~Hz}$, sine wave.

After the experimental testing, gathered data were processed. Data processing entailed calculation of the arithmetic mean of noticeability distance for each sound, as well as for the runs of the vehicle during which no alert sound was emitted. The results are shown in Fig. 6.

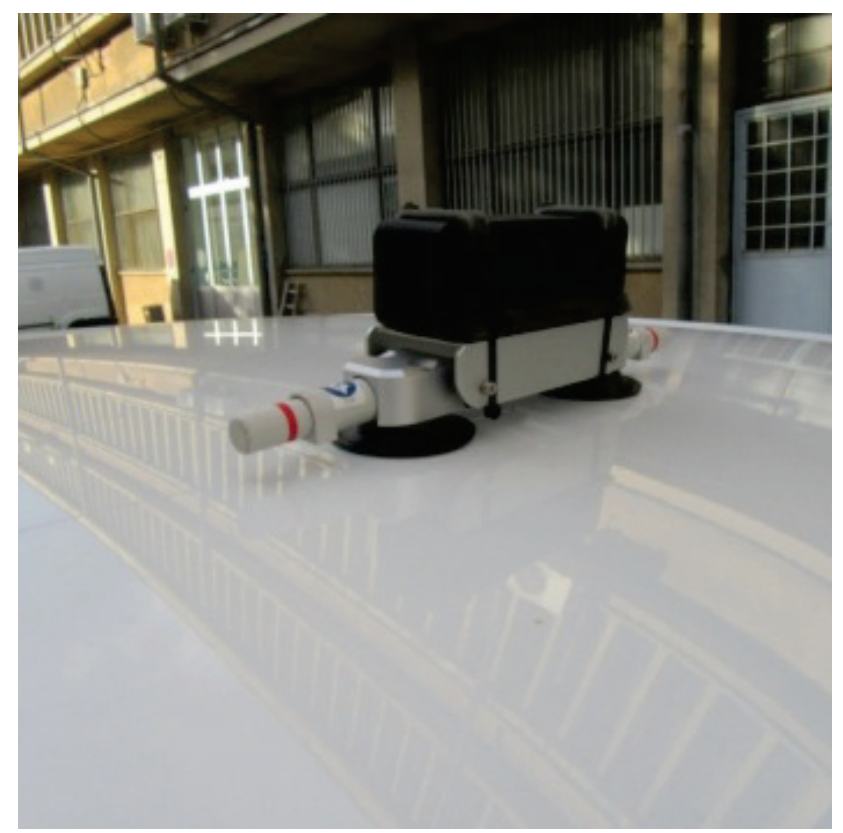

Figure 3 Alert-sound generating system used for testing

The experiment showed that the vehicle without an alert sound system, moving at the speed of $10 \mathrm{~km} / \mathrm{h}$ will not be timely noticed by the pedestrians. Data regarding the noticeability range (based on hearing alone) is shown in Fig. 6. The average distance at which the pedestrians noticed the vehicle that did not emit an alert sound was only $2,73 \mathrm{~m}$. Since at low speeds most of the noise is generated by the tires, we can be sure that the average noticeability distance for vehicles without an alert sound system would decrease with the improvement of the quality of the road. The real danger of "quiet" vehicles (the number of which will surely increase in the future) has been confirmed by this. The experiment confirmed that the vehicle will be noticed sooner if it has an alert sound system mounted. A distance of approximately $15 \mathrm{~m}$ is a significant increase compared to $2,73 \mathrm{~m}$ when the vehicle was noticed without an alert sound system. The experimentally presented distance disparity is a very important piece of information regarding traffic safety.

\section{CONCLUSION}

A conclusion can be made that an electric vehicle without an additional pedestrian alert sound system can hardly be noticeable by the pedestrians. By using a simple system, a drastic difference can be made regarding the distance at which a pedestrian can notice the oncoming vehicle by the sense of hearing alone, and with that an increase of traffic safety of electric vehicles. The observed disparity between 2,73 and $15 \mathrm{~m}$ is important in situations when the driver of the electric vehicle does not notice the pedestrian, and when the pedestrian is unaware of the oncoming vehicle.

a)
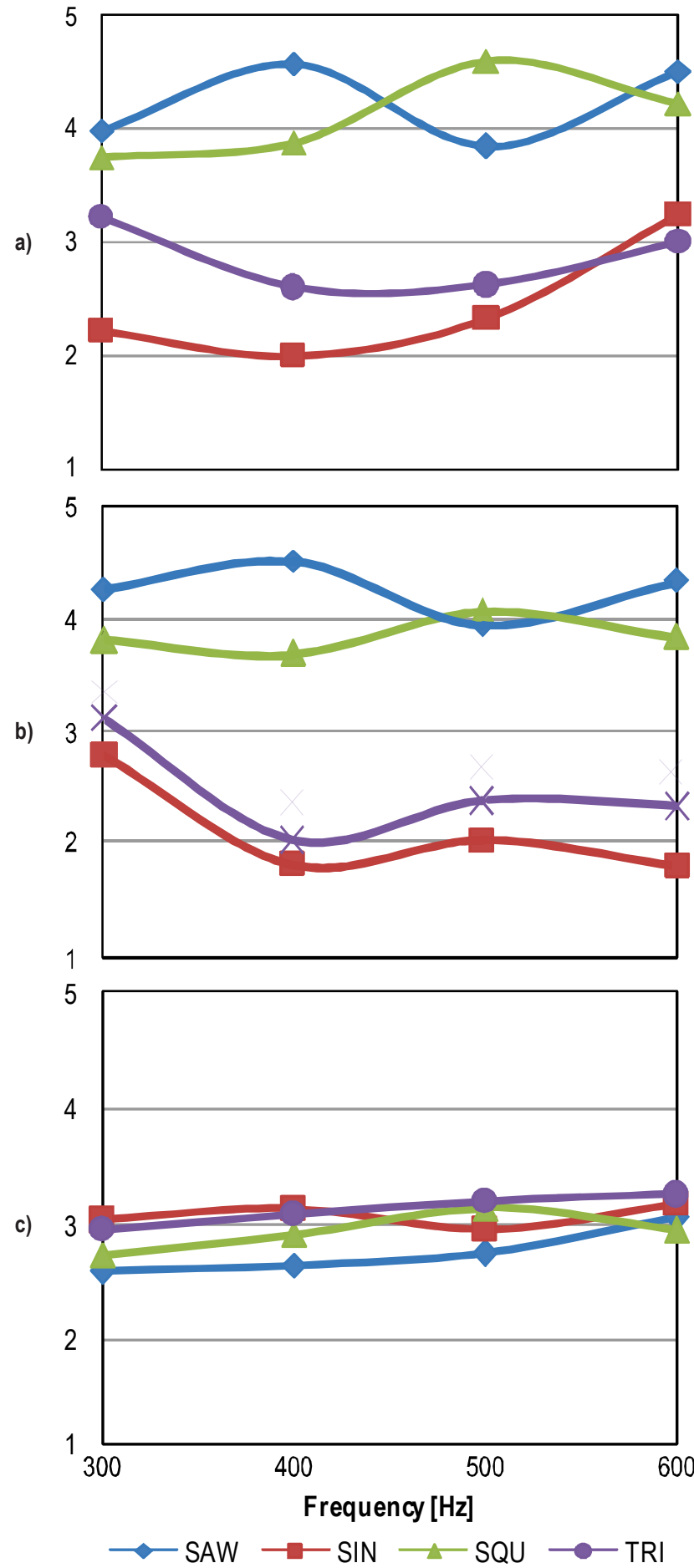

Figure 4 Sound ratings: (a) alertability, (b) irritancy, (c) authenticity)

The research also showed that the best result was obtained by sine wave tone with $400 \mathrm{~Hz}$ frequency. Slightly worse, but still good results were achieved with the same waveform at higher frequency of $600 \mathrm{~Hz}$ and with triangular wave at $400 \mathrm{~Hz}$ frequency. The difference between the best and the worst of three is $1,1 \mathrm{~m}$, which someone can regard as a small difference, but from the aspect of pedestrian safety it can be sometimes crucial. 


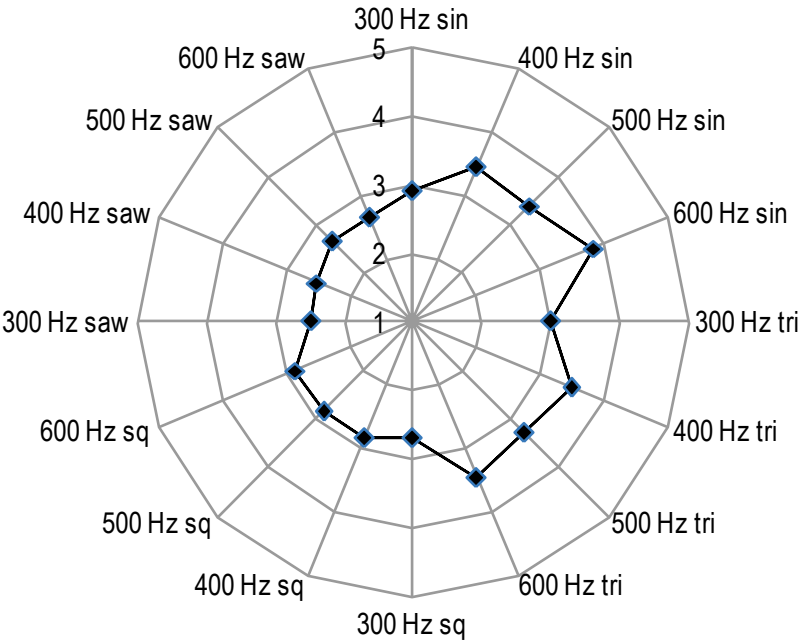

Figure 5 Overall sound ratings

Further research can be focused on a feedback alert sound. That kind of system would enable the varying of the alert sound intensity (and also the frequency) depending on the environmental noise (resulting from traffic, weather conditions etc.) intensity and other parameters. In addition, further improvements to the system can be made by introducing the dependency of sound parameters to vehicle speed and acceleration.

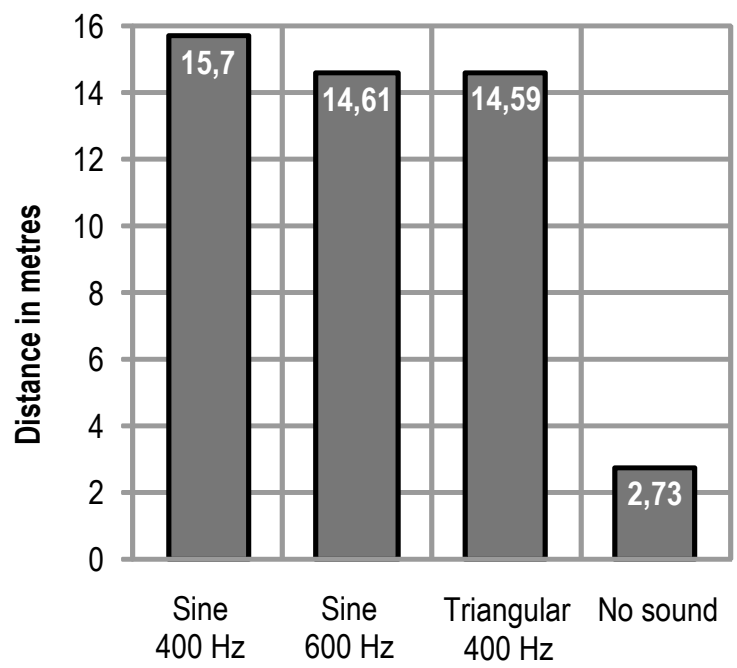

Figure 6 Mean values of the distance at which the electric vehicle (with and without an alert sound) was noticed

\section{Acknowledgments}

This paper is a result of the project financed by the Serbian Ministry of Education, Science and Technological Development (Project TR 35045 - "ScientificTechnological Support to Enhancing the Safety of Special Road and Rail Vehicles", project leader - prof. dr Vladimir Popović). The authors wish to express their gratitude to everyone who helped making this paper better.

\section{5}

\section{REFERENCES}

[1] Konet, H., Sato, M., Schiller, T., Christensen, A., Tabata, T., \& Kanuma, T. (2011). Development of approaching vehicle sound for pedestrians (VSP) for quiet electric vehicles. $S A E$ International Journal of Engines, 4(1), 1217-1224. https://doi.org/10.4271/2011-01-0928
[2] LeLong, J. (1999, December). Vehicle noise emission: Evaluation of tire/road-and motor-noise contributions. Paper presented at the $28^{\text {th }}$ International Congress and Exposition on Noise Control Engineering (Inter-Noise 1999), Fort Lauderdale, FL.

[3] Wu, J., Austin, R., \& Chen, C-L. (2011, October). Incidence rates of pedestrian and bicyclist crashes by hybrid electric passenger vehicles: an update. (DOT HS 811 526). Washington, DC: NHTSA.

[4] Wogalter, M. S., Lim, R. W., \& Nyeste, P. G. (2014). On the hazard of quiet vehicles to pedestrians and drivers. Applied Ergonomics, 45(5), 1306-1312. https://doi.org/10.1016/j.apergo.2013.08.002

[5] Experts from Japan. (2010, September). AVAS: Approaching vehicle audible system. Paper presented at the $52^{\text {nd }}$ session of UNECE Working Party on Noise (GRB), Geneve, Switzerland.

[6] Wogalter, M. S., Ornan, R. N., Lim, R. W., \& Chipley, M. R. (2001). On the risk of quiet vehicles to pedestrians and drivers. Proceedings of the Human Factors and Ergonomics Society, 45(23), 1685-1688. https://doi.org/10.1177/154193120104502326

[7] Lindvall, T., \& Radford, E. P. (1973). Measurement of annoyance due to exposure to environmental factors. Environmental Research, 6(1), 1-36. https://doi.org/10.1016/0013-9351(73)90014-5

[8] Tabata, T., Konet, H., \& Kanuma, T. (2011, May). Development of Nissan approaching vehicle sound for pedestrians. Paper presented at the $1^{\text {st }}$ International Electric Vehicle Technology Conference, Yokohama, Japan.

[9] Janković, S., Kleut, D., Blagojević, I., Stamenković, D., \& Vorotović, G. (2012). Application of vehicle's CAN based network in transmission service load data acquisition. Tehnički vjesnik, 19(2), 201-210.

[10] Kaliski, K., Old, I., \& Blomberg, L. (2012, August). Sound emissions from a plug-in electric vehicle. Paper presented at the $41^{\text {st }}$ International Congress and Exposition on Noise Control Engineering (Inter-Noise 2012), New York City, NY.

[11] Altinsoy, E. (2013, September). The detectability of conventional, hybrid and electric vehicle sounds by sighted, visually impaired and blind pedestrians. Paper presented at the $42^{\text {nd }}$ International Congress and Exposition on Noise Control Engineering (Inter-Noise 2013), Innsbruck, Austria.

[12] Emerson, R. W., Naghshineh, K., Hapeman, J., \& Wiener, W. (2011). A pilot study of pedestrians with visual impairments detecting traffic gaps and surges containing hybrid vehicles. Transportation Research Part F: Traffic Psychology and Behaviour, 14(2), 117-127. https://doi.org/10.1016/j.trf.2010.11.007

[13] Todorović, J. (1988). Motor vehicle braking: Theory, practice, maintanance and testing (in Serbian). Belgrade: Institute for Textbooks and Teaching Resources.

[14] Gordić, M., Stamenković, D., Popović, V., Muždeka, S., \& Mićović, A. (2017). Electric vehicle conversion: Optimisation of parameters in the design process. Tehnički vjesnik, 24(4), 1213-1219. https://doi.org/10.17559/TV-20160613131757

\section{Contact information}

Nikola FRLIĆ SEKULIĆ, PhD student

University of Belgrade, Faculty of Mechanical Engineering

Kraljice Marije 16, 11120 Belgrade, Serbia

nfrlic@mas.bg.ac.rs

Dr Ivan BLAGOJEVIĆ, Associate Professor

University of Belgrade, Faculty of Mechanical Engineering,

Kraljice Marije 16, 11120 Belgrade, Serbia

iblagojevic@mas.bg.ac.rs 
Dr Vladimir POPOVIĆ, Full Professor

University of Belgrade, Faculty of Mechanical Engineering,

Kraljice Marije 16, 11120 Belgrade, Serbia

vpopovic@mas.bg.ac.rs

Dragan STAMENKOVIĆ, teaching assistant

(Corresponding author)

University of Belgrade, Faculty of Mechanical Engineering,

Kraljice Marije 16, 11120 Belgrade, Serbia

dstamenkovic@mas.bg.ac.rs

Dr Slobodan JANKOVIĆ, Full Professor

University of Novi Sad, Technical Faculty "Mihajlo Pupin" Zrenjanin,

Đure Đakovića bb, 23101 Zrenjanin, Serbia

sjankovi@eunet.rs 